\title{
Microbial Community in Hyperalkaline Steel Slag-Fill Emulates Serpentinizing Springs
}

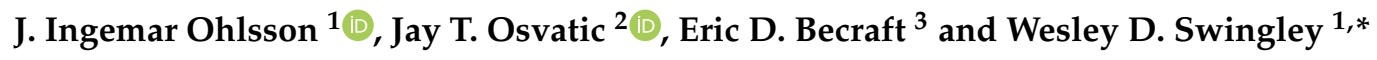 \\ 1 Department of Biological Sciences, Northern Illinois University, DeKalb, IL 60115, USA \\ 2 Centre for Microbiology and Environmental Systems Science, Division of Microbial Ecology, University of \\ Vienna, 1090 Vienna, Austria \\ 3 University of North Alabama, Florence, AL 35632, USA \\ * Correspondence: wswingley@niu.edu; Tel.: +1-209-777-4653
}

Received: 21 May 2019; Accepted: 21 June 2019; Published: 30 June 2019

\begin{abstract}
To date, a majority of studies of microbial life in hyperalkaline settings focus on environments that are also highly saline (haloalkaline). Haloalkaline conditions offer microbes abundant workarounds to maintain $\mathrm{pH}$ homeostasis, as salt ions can be exchanged for protons by dedicated antiporter proteins. Yet hyperalkaline freshwater systems also occur both naturally and anthropogenically, such as the slag fill aquifers around former Lake Calumet (Chicago, IL, USA). In this study, $16 \mathrm{~S}$ rRNA gene sequences and metagenomic sequence libraries were collected to assess the taxonomic composition and functional potential of microbes present in these slag-polluted waterways. Relative 16S rRNA gene abundances in Calumet sediment and water samples describe community compositions not significantly divergent from those in nearby circumneutral conditions. Major differences in composition are mainly driven by Proteobacteria, primarily one sequence cluster closely related to Hydrogenophaga, which comprises up to $85 \%$ of $16 \mathrm{~S}$ rRNA gene abundance in hyperalkaline surface sediments. Sequence identity indicates this novel species belongs to the recently established genus Serpentinomonas, a bacterial lineage associated with natural freshwater hyperalkaline serpentinizing springs.
\end{abstract}

Keywords: hyperalkaline; culture-independent; serpentinization; microbial diversity; Proteobacteria

\section{Introduction}

The Earth offers many natural habitats that appear very strange and inhospitable, at least to human observers. Microbes are routinely found surviving or even thriving in all extremes we encounter, short of the calderas of active volcanoes [1-3]. Industrial resource extraction and processing is the most common cause of anthropogenic extreme environments, yielding a variety of novel conditions, such as those associated with mine tailings [4], limestone processing [5], and slag piles [6]. We study natural extreme biomes, which typically establish over geological timescales, to learn how microbiomes evolve under these extremes. Anthropogenic environments, on the other hand, are established over mere years or decades, which allows us to observe how microbes and microbial communities rapidly adapt to persistent changes in their environment.

The former Calumet Wetlands abut the southwestern shore of Lake Michigan in the central US, encompassing parts of southern Chicago, IL and western Gary, IN [7]. Surviving parts of the wetlands include the Calumet River, Calumet Lake, Wolf Lake and Lake George, though very little of the area can now be described as marsh. As steel mills and other heavy industry expanded operations in the area, slag from steel production and other solid debris was used to fill in the marshes, simultaneously providing more land for development and disposing of industrial wastes "safely" by the standards of 
the time [8]. Much of this infill is now built over, but exposed berms of slag and coke ash can be found, such as the slag pile next to Wolf Lake.

The Calumet region has attracted some research in the decades following the cessation of industrial activities, with some work addressing concerns for human health and safety $[9,10]$, as residential neighborhoods cover much of the infilled land. This has, in turn, promoted an interest in the microbiology of the unique soils and waters in the Calumet Wetlands [8,11-13]. Whereas many natural hyperalkaline freshwater systems are found in remote locations [14,15] or deep in subsurface aquifers [16,17], Calumet is easily accessible from the Chicago area. This makes the site ideal for studying adaptations that permit microbial colonization of highly alkaline and heavily polluted environments, as well as the potential for enlisting indigenous microbes in the remediation of Calumet and similar sites. In addition to such potential ecological applications, determining the metabolic potential of microbes inhabiting extreme environments will inform not only our understanding of the physical limits of currently extant life, but also of the geological conditions that could give rise to and support life on Earth, and potentially on other moons and planets.

In this study, culture-independent techniques were used to investigate the microbiome of Indian Creek, near Lake Michigan in southern Chicago, IL, USA, which features hyperalkaline spring seeps fed by weathering of large tracts of exposed steel slag [12]. Metagenomic sequencing and 16S rRNA gene sequencing were performed on horizontal and vertical sediment transects near a shore featuring a high $\mathrm{pH}$ spring source, as well as several soil and water samples from nearby sites, including a lakeside recreational area. Bioinformatics analyses revealed that transects host many microbial taxa found in nearby circumneutral sediments up- and downstream along Indian Creek, though relative abundances vary by alkalinity. Phylum Proteobacteria is overrepresented in aerobic interfaces at the most alkaline site, with a bacterium closely related to Hydrogenophaga [18] and Serpentinomonas [14] dominating in these oxic, littoral sediments.

\section{Materials and Methods}

\subsection{Site Description and Sampling}

Previous research in the area of former Lake Calumet $[7,12,13,19]$ has indicated a significant microbial presence in hyperalkaline waters near large tracts of steel slag infill. This study uses sample material from four sites previously described in [19], identified as sites 1, 4, 5, and 7 (Figure 1A).

Site 1 is a hyperalkaline pond in Big Marsh Park, on the east shore of Lake Calumet. A loose precipitate of fine, loose calcium carbonate (hereafter referred to simply as calcite) covers the bottom of the pond, caused by the precipitation of atmospheric $\mathrm{CO}_{2}$ dissolved in the shallow water column due to the high $\mathrm{Ca}(\mathrm{OH})_{2}$ alkalinity. Reeds and shrubs grow along the pond banks, though leaves in direct contact with the water tend to bleach, and water plants do not survive within the abundant carbonate flocculent. Extreme concentrations of lead, zinc and calcium ions have been recorded from a groundwater observation well about $100 \mathrm{~m}$ away from the Site 1 sampling location. Groundwater $\mathrm{pH}$ under the slag is over 13, while surface $\mathrm{pH}$ in the pond is $\sim 11$ [19].

Site 4 is located on the south bank of Indian Creek, an artificial canal that drains Wolf Lake into Calumet River to the west (Figure 1B). The canal cuts through an undeveloped area that features 72 acres of exposed slag berms. Meteoric water filters through this slag bed, weathering the calcium-rich minerals and resulting in large amounts of $\mathrm{Ca}(\mathrm{OH})_{2}$ leaching into the canal through several spring seeps. Near the springs, calcite flocculent like that found at Site 1 fills Indian Creek to within $5-10 \mathrm{~cm}$ of the water surface, depending on season and rainfall (Figure 1B). Alkalinity at Site 4 also varies slightly with seasonal water levels, dropping in cases of heavy rains or snowmelt, but the canal water and sediment maintains a $\mathrm{pH} \geq 9.5$ throughout the year [19]. Groundwater under the slag bed maintains a $\mathrm{pH}$ at or above 13. As with Site 1, very high levels of lead, zinc and calcium are found in the groundwater. Since the alkalinity is caused by calcium hydroxide seeping out of the slag pile on the south bank, it attenuates quickly as spring seeps mix with the canal flow and atmospheric gases. The 
nearby vegetation effectively illustrates this, as lily pads can be found growing along the north canal bank, at which point the $\mathrm{pH}$ has decreased to circumneutral levels and calcite flocculent no longer covers the canal bottom (Figure 1B).
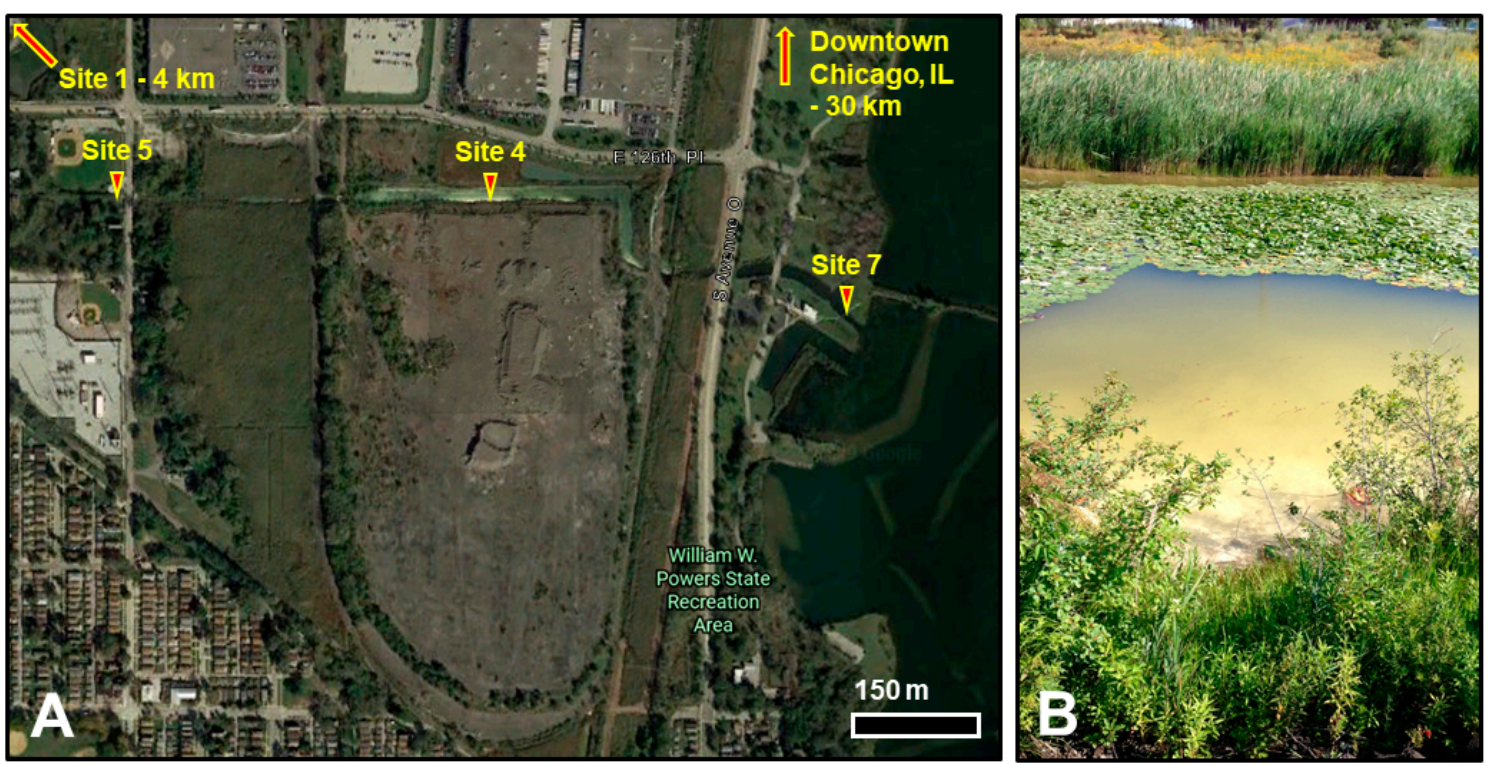

Figure 1. Indian Creek within the Calumet Wetlands in south Chicago, IL, USA. (A) Locations of sample sites around Indian Creek addressed in this work. Site 4 lies on the south bank of the canal, next to a 72-acre tract of exposed slag mounds. Hyperalkaline fluids seep out of the slag bank groundwater into the canal, raising $\mathrm{pH}$ above 9.5 year-round. Site 7 and Site 5 represent upstream and downstream control sites. Site 1, a hyperalkaline pond in Big Marsh Park, lies ca. $4 \mathrm{~km}$ to the northwest. Map data: Google. (B) View from the south bank at Site 4. Loose, yellow-white calcium carbonate flocculent fills the canal to a depth of $>1$ mear the spring seeps.

Site 5 is located along the north shore of Indian Creek, approximately $500 \mathrm{~m}$ downstream of Site 4, adjacent to a baseball field. Some calcite precipitation can still be seen, likely washed downstream from the slag infill, but it is far enough downstream that plants and wildlife appear unaffected by the upstream slag bed, and $\mathrm{pH}$ and metal concentrations have normalized [19].

Site 7 lies upstream of Site 4 on the western side of Wolf Lake in the William W. Powers State Recreational Area, near the mouth of Indian Creek. The lake's water is circumneutral (pH 7-9) and negligibly affected by slag fills in the area [19]. The lake is populated with various fish and other aquatic life that draws visitors for recreational fishing.

Samples were collected over four trips between 2013-2015 (Table S1). In August 2013, soil and water samples were acquired from all four sites. Sites 5 and 7 were treated as examples of "control conditions", with $\mathrm{pH}$ and water chemistry relatively unaffected by slag weathering byproducts. Additionally, horizontal and vertical transects were gathered at Site 4 . For the horizontal transect, soil and sediment was sampled at points $0 \mathrm{~cm}, 10 \mathrm{~cm}, 20 \mathrm{~cm}$ and $35 \mathrm{~cm}$ starting on the shore and continuing into the waterway adjacent to a surface spring, with the waterline at approximately $15 \mathrm{~cm}$ along the transect. At each transect point, the upper $2-5 \mathrm{~cm}$ of sediment was cored with a sterile $15 \mathrm{~mL}$ Falcon tube (Corning Inc., Corning, NY, USA). To limit the risk of cross-contamination, tubes were transported in factory packaging to the collection sites and handled with sterile procedures during sampling. For the vertical transect, an alcohol-sterilized $3 \times 30 \mathrm{~cm}$ circular PVC pipe was driven into the sediment $\sim 40 \mathrm{~cm}$ from the bank, capped at both ends, and kept vertical until it could be frozen, sectioned, and sampled in top, middle and bottom sections (approximately $2 \mathrm{~h}$ after sampling). Each section was sampled from the center of the core, in order to minimize contamination. 
In April 2014, two horizontal transects were recovered at separate Site 4 spring seeps, as described above, but sampled at $5 \mathrm{~cm}$ intervals along the same $35 \mathrm{~cm}$ transect. Another vertical transect was recovered in the same manner as above, frozen, and sectioned into $3 \mathrm{~cm}$ segments before sampling.

In July 2014, another horizontal transect was recovered at the first spring sampled in 2013. In addition, water samples were gathered from the canal at points up- and downstream of Site 4, at the springs sampled in April 2014 transects, and at the water-flocculent interface.

In March 2015, a larger vertical transect was collected, using an alcohol-sterilized $7.5 \mathrm{~cm} \times 60 \mathrm{~cm}$ PVC pipe. After freezing, the core was sectioned into inch-thick segments $(2.54 \mathrm{~cm})$ before sampling from the center of the core. Comprehensive site information is available in Table S1.

\subsection{DNA Extraction and $16 S$ rRNA Gene Amplification and Sequencing}

DNA was extracted using QIAgen PowerSoil kits (QIAgen, Venlo, The Netherlands), following the standard protocol. The $16 \mathrm{~S}$ small subunit ribosomal RNA gene $\mathrm{V} 4$ hypervariable region was targeted for PCR amplification using primers 515F and 806R [20]. Template and primers were combined with QIAgen MasterMix (company info) and MicroPure (MicroPure Filtration Inc., Cleveland, OH, USA) filtered water according to the standard protocols for MasterMix, to a total volume of $25 \mu \mathrm{L}$. Reactions were conducted in an Eppendorf thermocycler, over 30 cycles of: $30 \mathrm{~s}$ denaturation at $95^{\circ} \mathrm{C}, 60 \mathrm{~s}$ annealing at $55^{\circ} \mathrm{C}$, and $60 \mathrm{~s}$ elongation at $68^{\circ} \mathrm{C}$. Control reactions were prepared for each PCR run, using previously sequenced soil extract as a positive control template, and replacing the template with MicroPure water for a negative control. Successful amplification of the targeted fragment was verified by electrophoresis, before samples were sequenced as $150 \mathrm{bp}$ mate pairs using Illumina MiSeq (Illumina Inc., San Diego, CA, USA). Samples collected in August 2013 were sequenced by Argonne National Laboratory (Lemont, IL, USA), while all subsequent sequencing was carried out by the University of Illinois Chicago Sequencing Core (Chicago, IL, USA).

\section{3. $16 S$ rRNA Gene Classification and Analysis}

PCR amplified 16S gene reads were classified using a local install of the RDP Classifier v2.7 [21], with default settings (root confidence threshold 50\%). Classifier outputs were parsed and summed with custom Perl scripts to generate absolute counts of sequences matching each taxon in each sample, for the taxonomic levels of phylum, class, order, family and genus.

Genus-level taxonomic assignments were used in R v3.6.0 [22] to generate diversity measures (Genus counts, Pielou's evenness index, and Shannon diversity index) for eight geochemical categories of samples, indicating sample type (soil, water or sediment) and origin (transect position). Diversity measures were generated with the microbiome R package [23]. A principal components analysis (PCA) plot was generated for the genus abundances (grouped by the same categories) with the R built-in prcomp function and plotted using ggbiplot [24]. A non-metric multi-dimensional scaling (NMDS) analysis was also applied to genus-level taxon counts (normalized to relative abundances) using the metaMDS function in the $\mathrm{R}$ vegan package [25].

Pairwise Wilcoxon signed-rank tests were performed for each diversity metric, to determine statistical similarities between groups. An analysis of similarities (ANOSIM) was performed in R vegan, to directly test the differences between communities in terms of community composition. Default parameters were used for all analyses.

\subsection{Metagenomic Sequencing, Assembly, and Analysis}

Metagenome sequencing was carried out at the University of Illinois Chicago Sequencing Core (Chicago, IL, USA), on the Illumina MiSeq (Illumina Inc.) platform. Mate-pairs of $150 \mathrm{bp}$ were sequenced with an average insert size of $250 \mathrm{bp}$, which resulted in $102 \mathrm{bp}$ paired-end reads after barcodes and adapter sequences were removed by the sequencing facility.

14 sets of $102 \mathrm{bp}$ paired-end read sets were used for metagenomic assembly. De novo assemblies were generated for each read set using the SPAdes assembler package v3.1.0 [26], with default 
parameters (k-mer sizes 21, 33, 55) and automatic coverage estimation. Paired-end reads were included without overlapping prior to assembly.

After assembly, each scaffold set generated was partitioned into sequence bins with MaxBin 2.0 [27], which uses tetranucleotide frequencies to recover draft genomes. Ribosomal RNA genes were called from each bin using Barrnap v0.9 [28], and any 16S rRNA genes detected were classified with the RDP Classifier v2.7, in order to assign putative taxonomic identities to the bins. Any sequence bin containing more than one identifiable $16 \mathrm{~S}$ rRNA gene was considered chimeric.

A partial Hydrogenophaga genome was extended by read recruitment from all Site 4 read sets. Assembled contigs containing 16S rRNA genes classified as Hydrogenophaga, detected by BLASTn alignment [29] to 16S rRNA gene reads from earlier analyses (see 2.3) were used to train a multilayer perceptron (MLP) machine-learning algorithm in WEKA [30]. As outlined in Becraft et al. [31], the trained MLP was used to recruit more reads from all read sets. The extended read set was then reassembled in SPAdes, with standard parameters, and with the training contig set included as trusted sequences.

The 16S rRNA gene included in this draft genome was aligned in MEGA 6 [32] with a collection of representative sequences from families in order Burkholderiales (retrieved from the RDP Hierarchy Browser [33]), documented mesophilic members of genus Hydrogenophaga (retrieved from NCBI Gene [34]), and predicted 16S rRNA genes from three Serpentinomonas strains cultured from the Cedars, CA, USA [14]. Alignment was performed with the MUSCLE algorithm, using UPGMA clustering, with a gap open penalty of -400 and no gap extension penalty. The alignment was used to create a Maximum Likelihood phylogenetic tree (also in MEGA 6), to elucidate the placement of this draft genome in relation to genera Hydrogenophaga and Serpentinomonas. No gaps or mismatches were stripped before phylogenetic reconstruction. Tree generation used the Maximum Likelihood method with Tamura-Nei nucleotide substitution model. Initial trees for heuristic search were constructed using the Neighbor Joining method applied to a matrix of pairwise sequence distances estimated by Maximum Composite Likelihood [32]. Bootstrap support values were generated over 1000 replications.

The draft genome was submitted to RAST [35] for automated gene annotation. RAST annotations are accessible from the guest account under ID 6666666.223158-Hydrogenophaga sp.

Basic assembly statistics, including contig and scaffold lengths, total assembly lengths, N50, and L50, were generated for each assembly with custom Perl, Python and BASH scripts. Genome completeness and contamination estimates for binned contig sets and the Hydrogenophaga assembly were generated with CheckM [36], using reference set of 139 conserved single copy genes (CSCGs) common to all Bacteria. Metagenomic sequence reads are deposited at NCBI under accession number PRJNA548586.

\section{Results}

\section{1. $16 S$ rRNA Gene Analysis}

Relative 16S rRNA gene abundances for both neutral and alkaline sites indicate communities consist primarily of seven bacterial phyla: Acidobacteria, Actinobacteria, Bacteroidetes, Cyanobacteria (and eukaryote chloroplasts), Firmicutes, Proteobacteria and Verrucomicrobia (Figure 2, Figures S1 and S2; Table S2).

Most notably, class Betaproteobacteria are present at minimum 20\% in circumneutral sites, and overrepresented in certain segments at Site 4 (Figures 2 and 3), specifically in sediments near the waterline. Actinobacteria and Bacteroidetes are also present at significant abundance in most samples, though Actinobacteria abundance is much lower in neutral soil samples (S5S, S7S), while these samples have a higher relative abundance of Acidobacteria. At points ca. $5 \mathrm{~cm}$ or deeper below the soil surface, or under at least $10 \mathrm{~cm}$ of water column, Firmicutes and Bacteroidetes are most prevalent (Figure 4). 


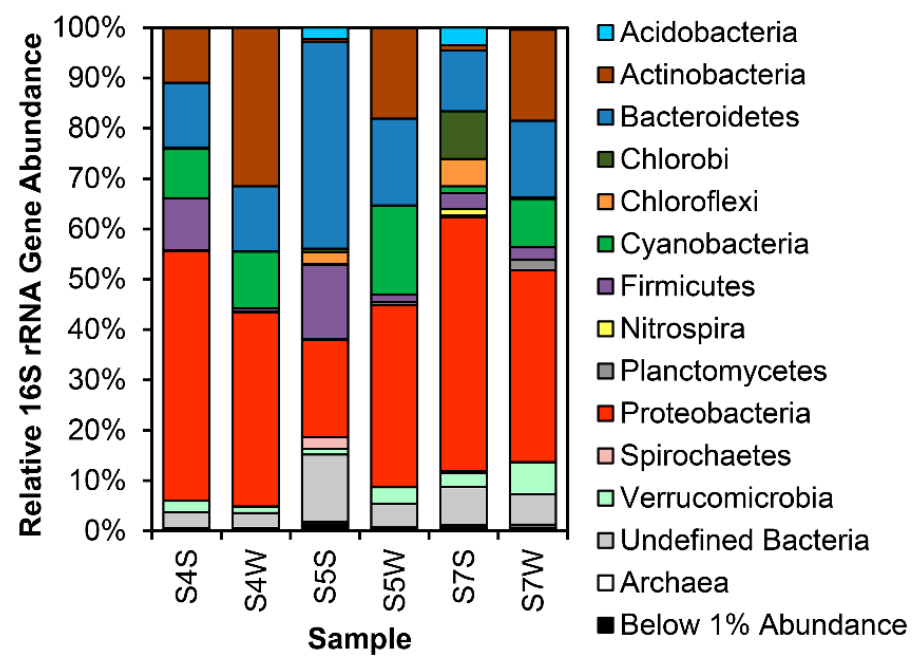

Figure 2. Phylum-level 16S rRNA gene relative abundances at sites 4, 5 and 7 around the Calumet Wetlands. All samples were collected in August 2013. S*W and $S^{*} S$ denote soil and water samples from the corresponding site.
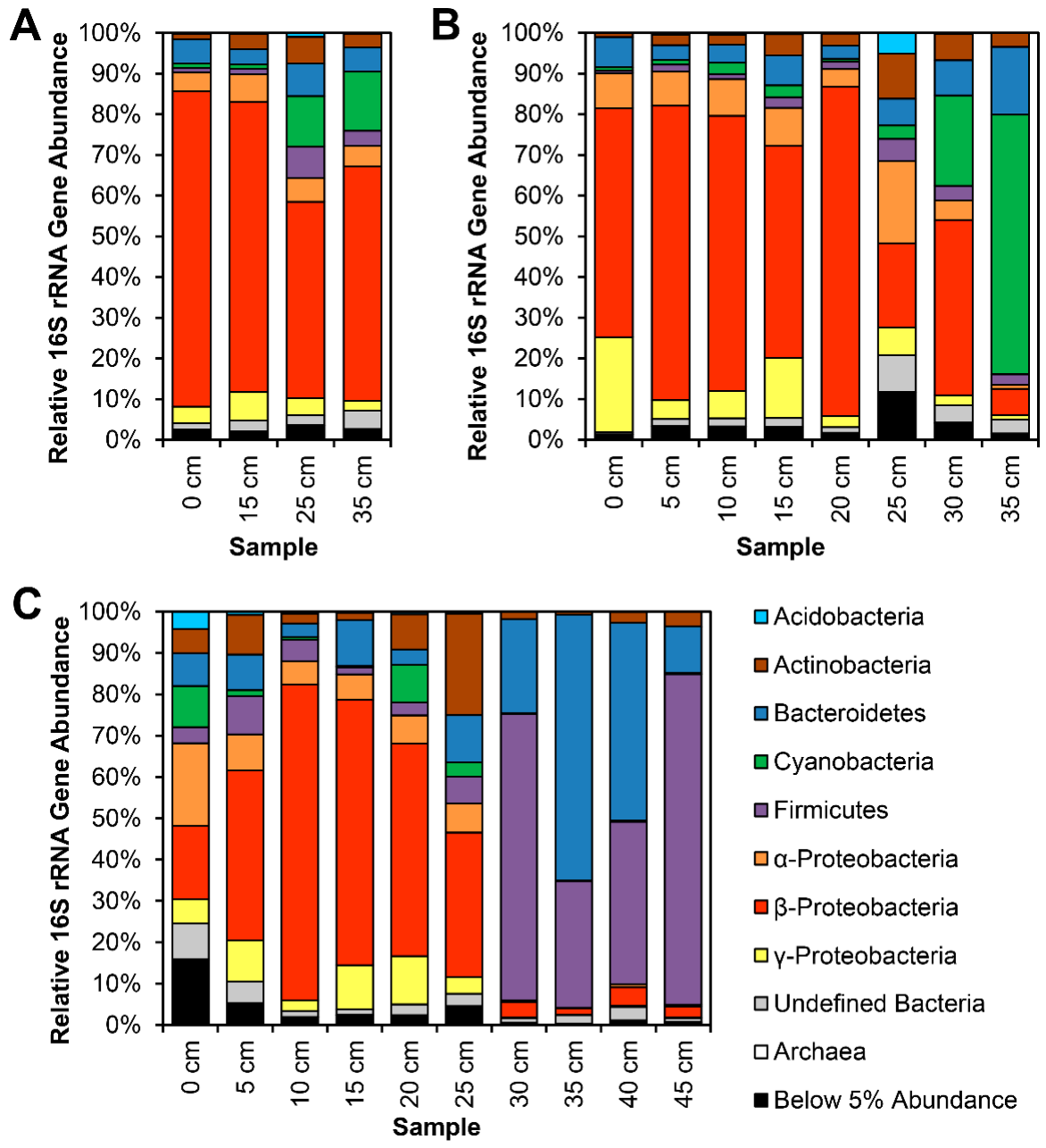

Figure 3. Phylum- and Proteobacterial class-level 16S rRNA gene relative abundances in three horizontal transects collected at Site 4: (A) $35 \mathrm{~cm}$ transect collected at Spring A in April 2014. (B) $35 \mathrm{~cm}$ transect collected at Spring B in April 2014. (C) $45 \mathrm{~cm}$ transect collected at Spring A in July 2014. Transects started inland at each spring seep, ca. $15 \mathrm{~cm}$ from the waterline. Samples were collected from the top layer of soil (on land) or upper layer of sediment (in the canal water column). 

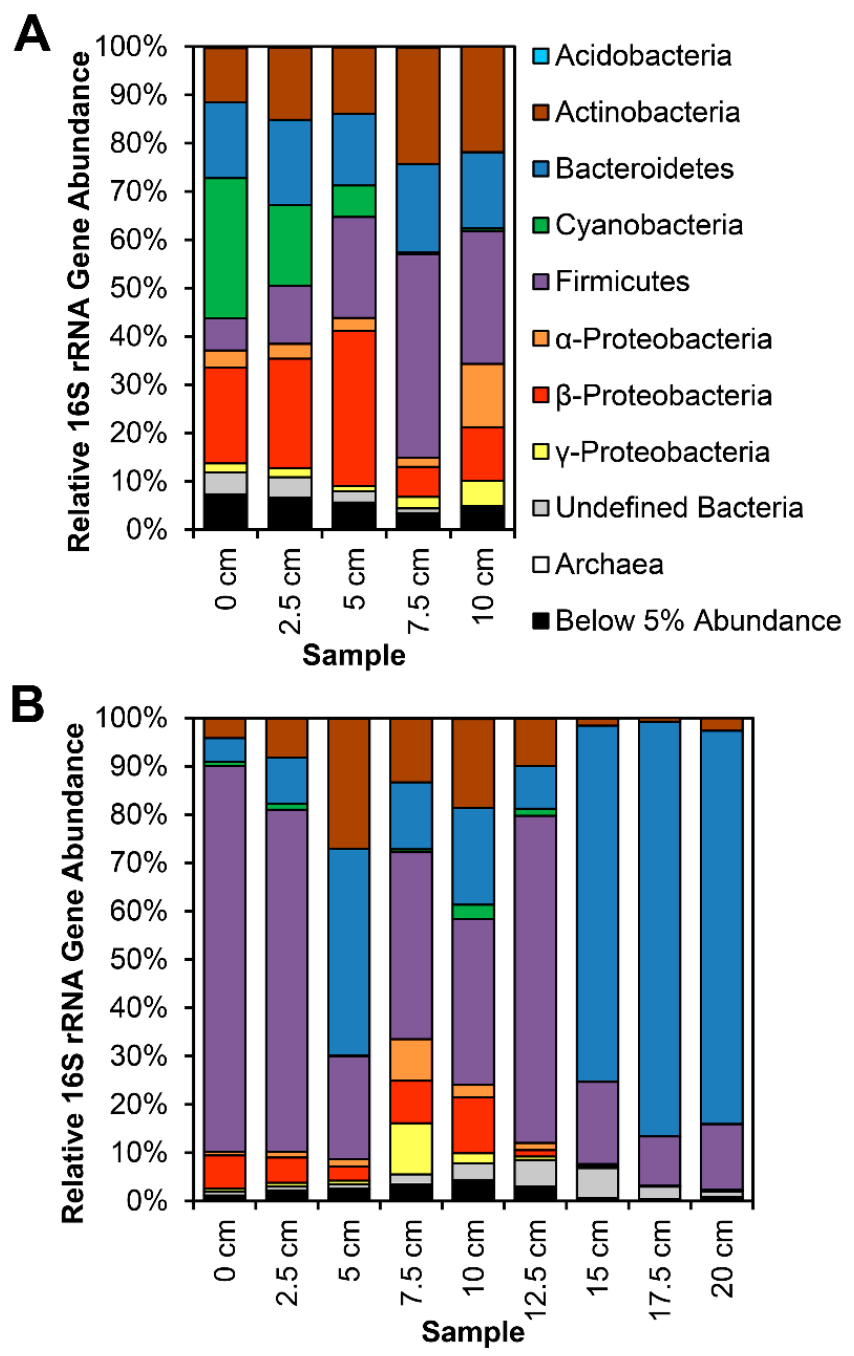

Figure 4. Phylum- and Proteobacterial class-level 16S rRNA gene relative abundances in two vertical transects collected at Site 4: (A) $3 \mathrm{~cm}$ diameter core collected in April 2014; (B) $7.5 \mathrm{~cm}$ diameter core collected in March 2015. Depth indicates the top side of each core segment, starting at the top of the calcium carbonate flocculent. Water column is not included, but averaged $5-10 \mathrm{~cm}$ above sediment.

PCA plots of all samples based on genus abundances (Figure 5) abstract taxonomic detail in favor of highlighting similarities between samples. Principal components 1 and 2 explain $48.3 \%$ and $17.3 \%$ of variance, respectively. Samples generally clustered by sample type, alkalinity, and geographical origin, with the notable exception of a cluster containing circumneutral soil and water samples together with Site 4 hyperalkaline water (hereafter called the "neutral cluster"). Horizontal transects samples are tightly clustered, but spread across PC1, with the submerged sediment samples frequently clustering with the neutral cluster. The vertical transect samples are the most dispersed, especially along PC2, with the deepest samples typically clustering with the neutral cluster. 


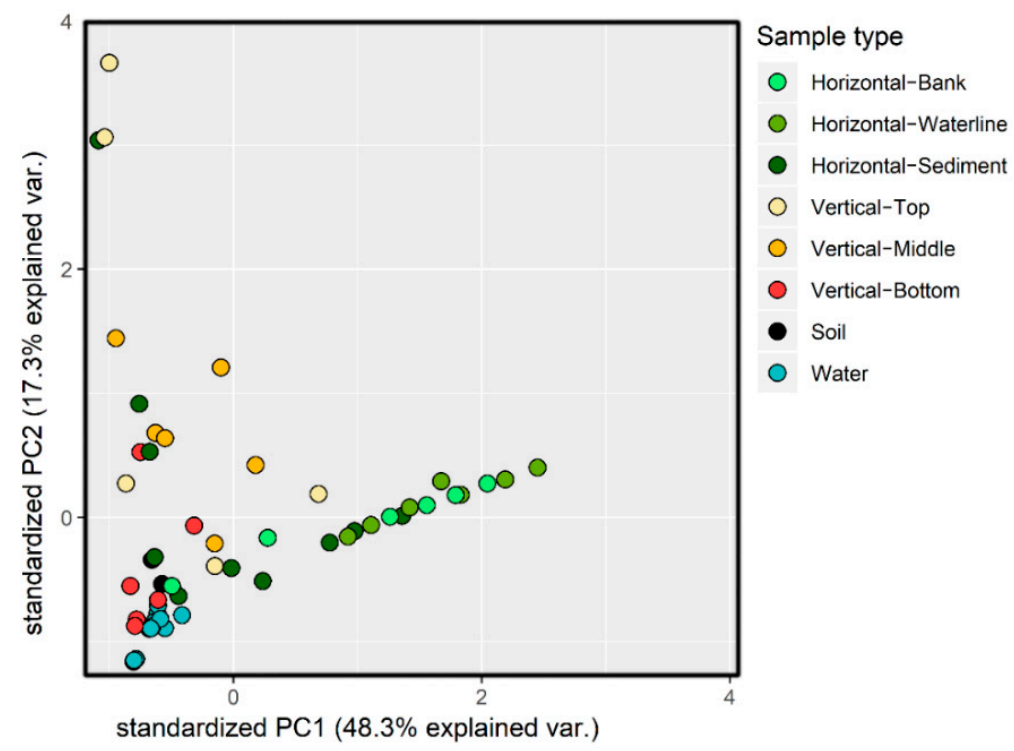

Figure 5. PCA plot of genus-level $16 \mathrm{~S}$ rRNA gene abundance data for all Calumet area samples. Principle components 1 and 2 shown, which together explain $65.6 \%$ of variance.

In the NMDS plot (Figure 6), samples from Sites 4 were grouped by oxygen access, to clarify important differences within the alkaline environment. Anoxic alkaline samples, from deeper sediments and soil, show a wide spread, overlapping to some degree with all other groups. Water samples and oxic alkaline samples each cluster toward separate edges of the anoxic community, with no overlap between the two. The oxic alkaline samples, from the bank and waterline of Site 4, are very tightly clustered.

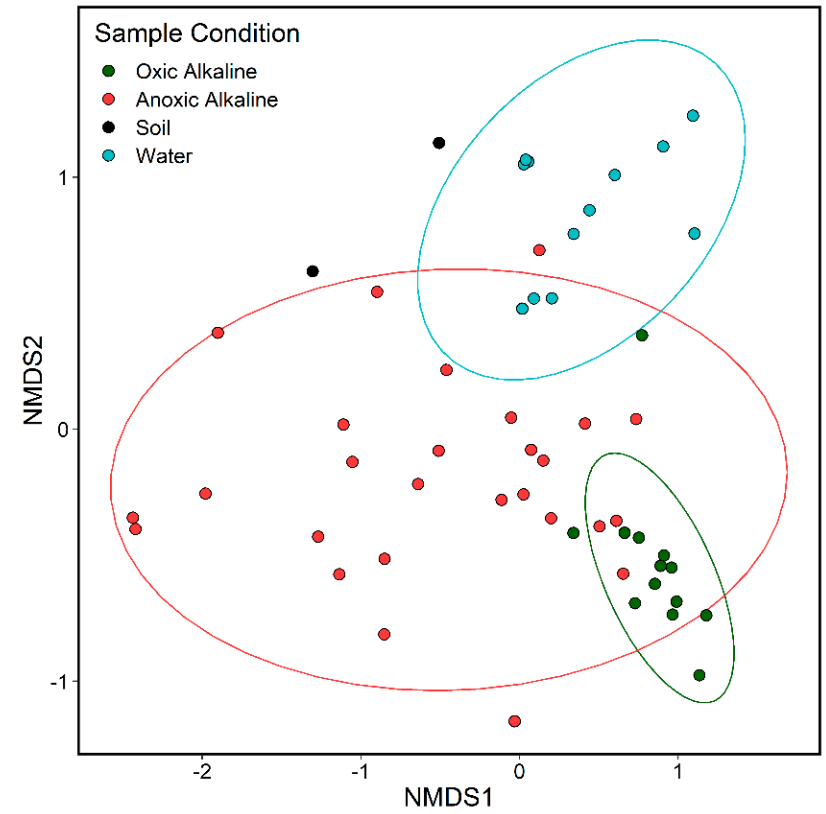

Figure 6. Non-Metric Multi-Dimensional Scaling plot of Calumet sites using Bray-Curtis distance, grouped by physical conditions of samples. "Oxic Alkaline" corresponds to the Horizontal Bank/Waterline samples, "Anoxic Alkaline" corresponds to Horizontal Sediment and all Vertical transect samples. Ellipses represent 95\% confidence intervals for the NMDS coordinates.

Shannon diversity distributions (Figure 7A) based on genus identities for soils and waters, along with middle segments of vertical transects, have a narrow range of diversity with means ca. 3.5. Other samples have much wider ranges, with lower means ca. 2.5. However, the only statistically 
significant difference (at $5 \%$ significance by pairwise Wilcoxon signed-rank test) was between the waterline at Site 4 and the open water sample cohort (both circumneutral and alkaline). Water samples also have significantly greater Pielou evenness than waterline samples (Figure 7B). While evenness is generally greater in vertical transect middle layers and in neutral soil samples, these differences were not statistically significant. While there are no statistically significant differences in genus richness among sample cohorts (Figure 7C), mean richness is highest in neutral soils (ca. 680) and lowest in the bottom vertical transect layers (ca. 220). Remaining samples have largely overlapping richness distributions arrayed between these extremes.

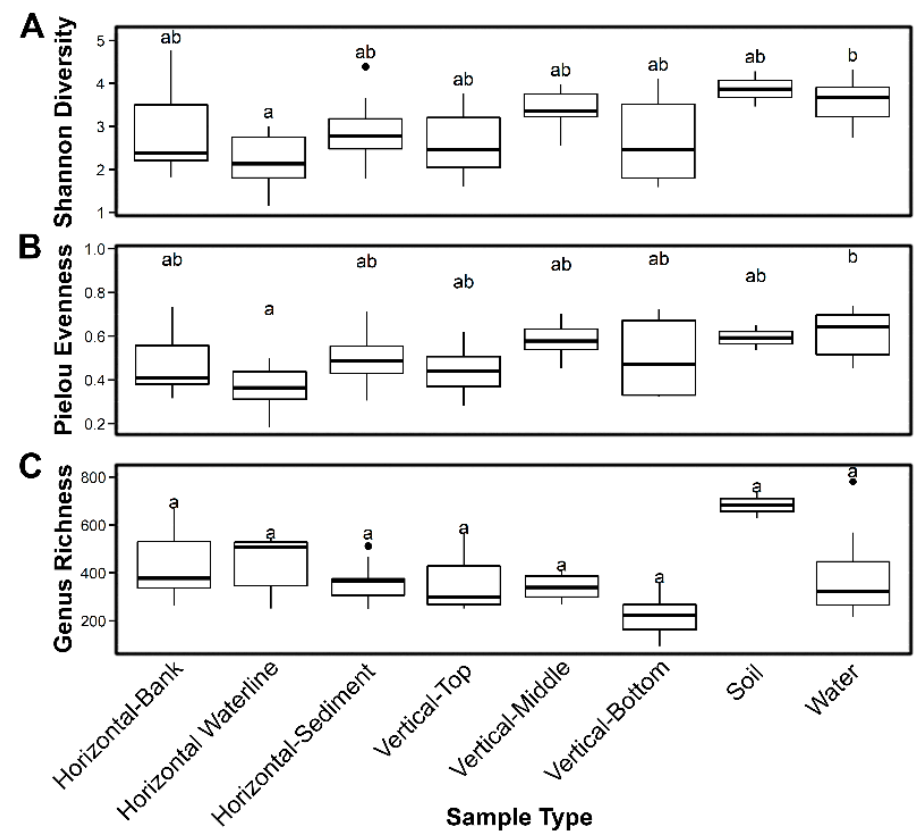

Figure 7. Genus-level statistical measurements of Calumet samples: (A) Shannon (alpha) diversity; (B) Pielou evenness; and (C) richness. Means are marked with a heavy black line, and hinges indicate the first and third quartiles. Whiskers indicate the range of values outside these quartiles. Outliers (farther than $1.5 \times$ the interquartile range) are indicated by black circles. Similarity groups at $95 \%$ confidence are indicated by letters $a$ and $b$.

ANOSIM results (Figure S3) shows that mean difference between samples is higher than the differences within the oxic alkaline, anoxic alkaline and water sample groups. Oxic alkaline samples have the least within-group difference. Each group can be considered distinct, though their quartiles show some overlap. This assessment does not extend to circumneutral soil samples, of which there were too few to estimate the distribution.

\subsection{Metagenomic Analysis}

De novo assembly produced a total of $1.6 \mathrm{Gbp}$ in 3.6 million sequence scaffolds between the 14 input read sets. Assembly statistics are summarized in Table 1 . The highest N50 values were from samples $\mathrm{S} 435 \mathrm{~cm}(\mathrm{~N} 50=17,104), \mathrm{S} 410 \mathrm{~cm}(\mathrm{~N} 50=11,177)$ and S40 cm $(\mathrm{N} 50=10,449)$, all horizontal transect samples from Site 4 . Sequences from water samples uniformly produced fragmented assemblies with N50 $\leq 896$, and circumneutral soil metagenomes produced N50 $\leq 488$, supporting the suggestion that these samples had higher genetic diversity (Figure 7A). Total scaffold length was very high (216-766 million bp) in all circumneutral metagenomes except S7W (4.8 million bp), while the average for all read sets was $117,890,266.79 \mathrm{bp}$. 
Table 1. Metagenomic assembly statistics for Calumet read sets.

\begin{tabular}{ccccccc}
\hline Read Set & $\begin{array}{c}\text { Total } \\
\text { Sequence } \\
\text { Input (bp) }\end{array}$ & $\begin{array}{c}\text { Total } \\
\text { Scaffold } \\
\text { Length (bp) }\end{array}$ & $\begin{array}{c}\text { Number of } \\
\text { Scaffolds }\end{array}$ & $\begin{array}{c}\text { Maximum } \\
\text { Contig } \\
\text { Length (bp) }\end{array}$ & N50 (bp) & L50 (bp) \\
\hline S1S & $4,819,674,420$ & $9,869,266$ & 8842 & 70,488 & 4776 & 457 \\
S1W & $1,942,236,264$ & $96,016,654$ & 189,034 & 131,675 & 896 & 15,108 \\
S40cm & $6,321,349,632$ & $27,714,568$ & 7294 & 288,607 & 10,449 & 641 \\
S410cm & $1,138,541,340$ & $4,063,552$ & 2257 & 62,774 & 11,177 & 86 \\
S420cm & $8,551,723,860$ & $33,109,460$ & 39,264 & 137,610 & 3111 & 2415 \\
S435cm & $7,864,380,132$ & $31,171,314$ & 20,943 & 138,650 & 17,104 & 437 \\
S4S & $8,901,634,656$ & $17,907,967$ & 13,735 & 135,896 & 7433 & 522 \\
S4verticalbottom1 & $3,488,100,120$ & $45,790,429$ & 148,148 & 32,268 & 293 & 44,271 \\
S4verticaltop1 & $5,195,853,276$ & $11,790,385$ & 21,636 & 99,847 & 6486 & 372 \\
S4W & $781,642,320$ & $91,790,252$ & 237,098 & 42,452 & 363 & 58,467 \\
S5S & $7,256,817,336$ & $766,453,974$ & $1,650,212$ & 594,813 & 488 & 338,228 \\
S5W & $1,891,476,984$ & $216,488,361$ & 534,113 & 123,446 & 404 & 124,669 \\
S7S & $3,027,277,992$ & $293,538,298$ & 692,250 & 139,485 & 450 & 164,345 \\
S7W & $\mathbf{1 , 2 0 2 , 2 1 7 , 4 9 2}$ & $4,759,255$ & 17,534 & 36,970 & 259 & 6,864 \\
\hline Sum & $\mathbf{6 2 , 3 8 2 , 9 2 5 , 8 2 4}$ & $\mathbf{1 , 6 5 0 , 4 6 3 , 7 3 5}$ & $\mathbf{3 , 5 8 2 , 3 6 0}$ & $\mathbf{2 , 0 3 4 , 9 8 1}$ & & \\
\hline Average & $4,455,923,273.14117,890,266.79$ & $255,882.86$ & $145,355.79$ & 4549.21 & $54,063.00$ \\
\hline
\end{tabular}

Automated scaffold binning results are summarized in Table 2. MaxBin 2.0 generated 23 sequence bins for read set S5S, 0 bins for read set S7W, and 2-6 bins for each other read set. Barrnap detected 177 $16 \mathrm{~S}$ rRNA genes (2-42 genes per read set).

Table 2. Metagenomic binning statistics for Calumet read sets.

\begin{tabular}{ccccccc}
\hline Read Set & $\begin{array}{c}\text { Scaffold } \\
\text { Bins }\end{array}$ & $\begin{array}{c}\text { Detected } \\
\text { 16S rRNA } \\
\text { Genes }\end{array}$ & $\begin{array}{c}\text { Chimeric } \\
\text { Bins }\end{array}$ & $\begin{array}{c}\text { Average } \\
\text { Completeness }\end{array}$ & $\begin{array}{c}\text { Average } \\
\text { Genome } \\
\text { Size }\end{array}$ & $\begin{array}{c}\text { Average GC } \\
\text { Content }\end{array}$ \\
\hline S1S & 2 & 4 & 1 & $64.1 \%$ & $3,945,426$ & $63.5 \%$ \\
S1W & 6 & 11 & 2 & $75.2 \%$ & $3,808,967$ & $55.3 \%$ \\
S40cm & 4 & 12 & 1 & $36.5 \%$ & $3,072,671$ & $59.7 \%$ \\
S410cm & 2 & 2 & 0 & $49.1 \%$ & $1,787,619$ & $62.7 \%$ \\
S420cm & 3 & 19 & 1 & $50.2 \%$ & $4,217,172$ & $56.3 \%$ \\
S435cm & 5 & 22 & 3 & $81.3 \%$ & $4,979,437$ & $45.9 \%$ \\
S4S & 4 & 21 & 3 & $46.5 \%$ & $3,947,249$ & $51.6 \%$ \\
S4verticalbottom1 & 2 & 7 & 2 & $62.6 \%$ & $1,663,564$ & $50.2 \%$ \\
S4verticaltop1 & 2 & 10 & 1 & $74.3 \%$ & $4,420,534$ & $54.1 \%$ \\
S4W & 4 & 8 & 3 & $68.2 \%$ & $2,177,976$ & $48.3 \%$ \\
S5S & 23 & 42 & 4 & $72.9 \%$ & $3,830,319$ & $53.9 \%$ \\
S5W & 6 & 10 & 1 & $58.6 \%$ & $2,675,264$ & $46.0 \%$ \\
S7S & 4 & 9 & 2 & $75.0 \%$ & $4,072,426$ & $46.4 \%$ \\
\hline Sum & $\mathbf{6 7}$ & $\mathbf{1 7 7}$ & $\mathbf{2 4}$ & & & \\
\hline
\end{tabular}

Comparison of classifications of each rRNA gene sequence found 24 bins to be chimeric (0-4 bins per read set), as evidenced by presence of multiple incompatible classifications within the same bin. Only the $\$ 410 \mathrm{~cm}$ read set was free of chimeric bins. This read set produced only two bins, one of which was a near-complete draft Hydrogenophaga genome (97.2\% completeness, genome size 2.4 Mbp), while the other contained a single 16S rRNA gene that could only be confidently assigned to domain Archaea, with an estimated completeness only $0.9 \%$, and a genome size of $1.2 \mathrm{Mbp}$.

Read recruitment by multilayer perceptron produced another draft Hydrogenophaga genome with 2.9 Mbp genome size and 100\% completeness as reported by CheckM. RAST annotations showed the presence of putative carboxysome shell proteins and the large subunit of ribulose bisphosphate carboxylase, indicating the ability to fix inorganic carbon, and hyaA/hyaB hydrogen utilization genes. Presence of $\mathrm{CO}_{2}$ fixation subsystems without evidence of light-harvesting complexes suggests that these signatures are genuine, and not the result of cyanobacterial contamination in the assembly. These 
annotations match similar activity in Serpentinomonas strains reported in Suzuki et al. [14]. Other annotated functions include Gram-negative cell wall components, capsule- and EPS-related genes, several $\mathrm{ABC}$ transporters, metal compound resistance genes, and systems for chemotaxis and flagellar motility. Ten prophage genes were annotated, but no transposable elements. Sequence alignment with representatives of known Hydrogenophaga, Serpentinomonas and neighboring bacterial families produced a Maximum Likelihood phylogenetic tree showing the draft genome clustering within the Serpentinomonas clade (Figure 8) with S. mccroryi and S. rachei [14]. Serpentinomonas raichei and Serpentinomonas mccroryi were recently renamed, and are referred to as Comamonadaceae strains A1/H1 and B1 in the original publication [14].

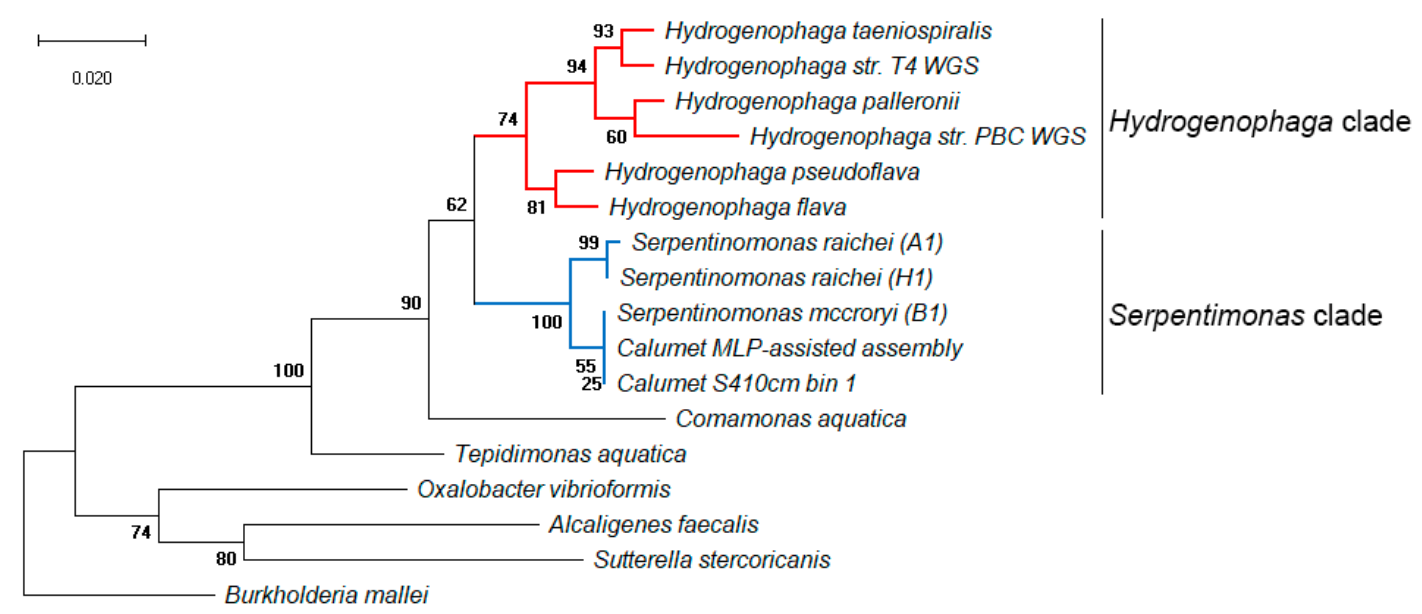

Figure 8. Maximum Likelihood phylogenetic tree of $16 \mathrm{~S}$ rRNA genes from select members of order Burkholderiales. Highlighted in red: Hydrogenophaga species in the NCBI database, typically not associated with extreme alkalinity. Highlighted in blue: the Calumet draft genomes, clustered with three Serpentinomonas strains isolated from the Cedars serpentinizing springs in California, USA. Serpentinomonas raichei was previously identified as Comamonadaceae strains A1/H1, and Serpentinomonas mccroryi as Comamonadaceae strain B1. Bootstrap support values from 1000 iterations are given in bold next to associated nodes.

\section{Discussion}

The microbial community at Calumet reflects striking similarities to nearby natural (or rather, not directly polluted) sites, suggesting that the microbial library of this damaged environment has persisted even through nearly 100 years of anthropogenic impact. Strong similarities between the microbial communities in the Calumet Wetlands' interconnected hydrological network (Figure 5), are a likely source of continual microbial input. Even if these organisms cannot take advantage of the hyperalkaline conditions at Site 4, their genetic material may remain trapped in the calcium carbonate sediments for long after their arrival. The relatively high rate of input to this system (Chicago receives $>90 \mathrm{~cm}$ of rain per year; www.weather.gov) makes the Calumet hyperalkaline sites unique in their proximity between neutral waters and such extreme alkalinity, and a perfect test bed for understanding extremophile adaptation and biogeography.

Scientific understanding of freshwater hyperalkaliphiles has much room for improvement, particularly in terms of shared traits among such organisms. While any bacterium that is able to survive at the high end of the $\mathrm{pH}$ scale can inform us about responses to alkaline stress, bacteria that thrive in such harsh conditions would be of interest for use in bioremediation of alkaline pollution. Once members of the microbiome at Indian Creek are established in culture, and their genomes are sequenced and annotated, it will be possible to investigate their growth behavior in detail and assess whether they can be used as a delivery vehicle for remediation strategies.

The differences between soil and water samples are, with a few exceptions, clearer than those between neutral and alkaline sites. Actinobacteria are virtually absent from Site 5 and 7 soil samples 
and "Cyanobacteria" (representing both Cyanobacteria and chloroplast genomes of eukaryotes, e.g., diatoms) are heavily reduced compared to their numbers in water samples from all studied sites. There is also a clear transition with vertical depth, as Proteobacteria give way to Bacteroidetes and Firmicutes in the deeper, increasingly anaerobic sediments (Figure 4).

The most striking feature of the $16 \mathrm{~S}$ rRNA gene survey is the dominance of a Betaproteobacterial lineage in oxic sediments at Site 4 , reaching as high abundance as $75-85 \%$ of the entire microbial community near the waterline around $15 \mathrm{~cm}$ along each transect (Figure 3). It appears that this bacterium, closely related to the genera Hydrogenophaga, is singularly adapted to the harsh conditions at Site 4. However, its metabolism is still reliant on abundant oxygen, given its disappearance in deeper samples. It may also require access both to water and the carbonate flocculent to grow. Culture-based studies of bacteria isolated from the Cedars, CA, USA [14] found three strains of Serpentinomonas actively colonizing calcium carbonate precipitates, with growth on solid media dependent on added carbonate. Solid-phase carbonate is generally not considered bioavailable at the $\mathrm{pH}$ levels of Indian Creek, as it is highly insoluble. The Site 4 Betaproteobacteria may also possess the uncommon ability to utilize solid carbonate precipitates as a carbon source, which would confer a major advantage in this environment, where other carbon sources are scarce. The mechanism by which Serpentinomonas takes up carbon from the flocculent is unclear, but all three strains from the Cedars possess carboxysome shell proteins and components of the RuBisCo enzyme[14], which suggests that they resolubilize carbonate ions before using traditional carbon fixation pathways to utilize the carbon content of the flocculent. Putative genes coding for all of these activities were also present in the Calumet metagenome assembly.

Principal component analysis of genus-level 16S rRNA abundances (Figure 5) showed soil and water samples clustered very tightly together with some deep vertical core segments. Horizontal transect samples plot along a very well-defined line, but the arrangement of bank, waterline and sediment sections of the horizontal transects along this vector does not correspond to their physical order. Considering that Proteobacteria abundances quickly give way to Firmicutes and Bacteroidetes (Figure 3) over a distance of $10 \mathrm{~cm}$, this linear cluster may be tied to oxygen availability affecting species richness. In the shallow, oxic sediment, Serpentinomonas is dominant, distancing the community as a whole from the more diverse, neutral environments. Diversity increases somewhat with depth, as oxygenation and Serpentinomonas declines. Alkalinity is also mitigated by calcite precipitation, as calcium ions are pulled out of solution by dissolved atmospheric $\mathrm{CO}_{2}$ [12]. Overall, this PCA reinforces the notion that microbial communities at Site 4 are related to nearby neutral environments, but combinations of geochemical conditions promote highly localized concentrations of certain specialized taxa.

NMDS (Figure 6) and ANOSIM (Figure S3) results also support the connection between Calumet sample groups. Confidence ellipses in the NMDS plot and group differences overlap noticeably between the oxic and anoxic alkaline samples, and the water sample cohort. Oxic alkaline samples are more distinct, due to being tightly grouped. This is most likely a result of the very narrow range of taxa at the Site 4 bank and waterline. This is the most selective segment of the hyperalkaline slag-fill waterway; in the main waterway, or deeper in the sediment, more varied communities can survive.

Metagenomic assembly of read sets from circumneutral samples produced the greatest total assembly lengths, but also the worst N50, indicating the assembled scaffolds were highly fragmentary (Table 1). This is likely due to the greater diversity and evenness of microbial communities at these sites, which means that "shotgun sequencing" methods are less likely to hit any given species. Water samples also had poor assembly performance, likely due to the dilute cell concentrations and lower total read count in these samples.

Metagenomes from the hyperalkaline soil and shallow sediments of Site 4, on the other hand, produced the three best assemblies, and other alkaline sample assemblies were of similar quality. This is likely an effect of high alkalinity restricting species richness by suppressing mesophilic species, which means that alkaliphiles had higher relative sequence coverage. Contrary to the difficulties of culturing extremophiles in a laboratory setting, culture-independent methods can be particularly 
effective in highly selective environments, where a small number of community members dominate, which bodes well for future applications of environmental metagenomics.

Automatic binning produced multiple scaffold bins for all read sets except S7W (Table 2), derived from water at Wolf Lake, likely due to the highly fragmented assembly caused by the diverse and dilute community structure in neutral waters. Given the generally diverse populations detected by $16 \mathrm{~S}$ rRNA gene sequencing, fragmented and chimeric bins might be expected, as great sequencing depth may be required to resolve complex metagenomes. However, a majority of these bins contained only one 16S rRNA gene, or several that had non-conflicting taxonomic assignments. Further analysis is needed, with direct sequence-based methods, to confirm whether or not these bins are truly chimeric, but this initial ribosomal RNA genotyping overview is promising.

The extreme overrepresentation of Hydrogenophaga-related species at the Site 4 waterline led to highly effective sequence coverage. One bin recovered from the Site 4 waterline represents a highly complete genome ( $97.2 \%$ completeness, $2.4 \mathrm{Mbp}$ ) assigned to genus Hydrogenophaga by the RDP Classifier. MLP read recruitment of Hydrogenophaga-tagged contigs also resulted in a highly complete draft genome (100\% completeness, $2.9 \mathrm{Mbp})$. Since genus Serpentinomonas was very recently established [14], the type strain sequences had yet to be added to RDP at the time of this analysis, but phylogenetic comparison (Figure 8) shows that the dominant species around the waterline at Site 4 is a close relative of $S$. mccroryi.

The presence of Serpentimonas, specialized at surviving in naturally occurring serpentinizing springs, in an anthropogenic Site of industrial waste pollution thousands of miles from the nearest serpentinizing site, is perhaps surprising, yet the similarity between conditions in these two disparate environments are similar enough to promote this organism above the community background. Its presence at such distant sites makes a strong argument for the Baas-Becking hypothesis that states "everything is everywhere, but the environment selects" [37], at least for these related extreme ecosystems. Both types of sites host hyperalkaline aquifers, at $\mathrm{pH} 13$ in the case of Calumet and around $\mathrm{pH} 11$ for most serpentinization sites [17,38,39]. Neither Indian Creek nor terrestrial serpentinizing springs have high levels of salinity $[17,19,39]$, meaning alkaliphiles in these waters cannot rely on antiporter proteins exchanging sodium ions for protons across the cell membrane to maintain $\mathrm{pH}$ homeostasis [40]. For haloalkaliphiles in soda lakes (e.g., Mono Lake, CA, USA [41]), sodium exchange is a readily available tool [42], but in freshwater systems, like the ones studied here, unknown mechanisms will be required to maintain homeostasis. Both are recognized by large amounts of calcite precipitation, though in natural sites the precipitates often build up persistent travertine deposits or carbonate crusts or sinters [15], as opposed to the loose, snowy flocculent in Indian Creek, which is likely due to the low persistence time of this anthropogenic system. Copious hydrogen is a key signature of serpentinizing systems [14,39], and studies of the slag weathering phenomenon in Calumet suggest that slag-water interactions may release hydrogen gas [12], but its presence in the sediments of Indian Creek has yet to be confirmed.

The slag-water interface in the Calumet area may be similar enough to serpentinizing bedrock systems to allow colonization by serpentinization-selected species. More studies are needed to determine whether the elevated levels of heavy metals and other anthropogenic hazards $[12,19]$ have forced this novel Serpentinomonas genome to develop further adaptations to dominate this unique hyperalkaline system. The success of Serpentinomonas at Indian Creek has a wide variety of implications, beyond the evolutionary history of the species itself. Notably, it associates serpentinization-related bacterial life with anthropogenic deposits (specifically, the slag infill) which are chemically and geographically distinct from the ultramafic olivine minerals that drive natural serpentinization [12,43]. This affects our understanding as high-pH, hydrogen-rich environments as potential sites for the origin of life, by broadening the gallery of minerals that can support such conditions beyond forsterite and fayalite, which in solid solution form olivine. 


\section{Conclusions}

This study has shown that, despite the extreme alkalinity, carbonate precipitation and heavy metal pollution at the Calumet Wetlands Site 4, microbial communities at this Site remain diverse and strongly correlated with those in nearby circumneutral sites. Despite the apparent similarities in communities from both alkaline and circumneutral conditions, a few species thrive in certain hyperalkaline microenvironments at Indian Creek, particularly a Betaproteobacterium related to genus Serpentinomonas. Like its recently-described sister taxa, this species thrives in close association with the carbonate flocculent, a rarely used carbon source among bacteria. The two draft genomes established here provide more resources for investigating the mechanisms that allow Serpentinomonas to survive extremely alkaline $\mathrm{pH}$ without the aid of abundant salt ions, while subsisting on recalcitrant carbon sources. Understanding these survival mechanisms opens new avenues of research into bioremediation of hyperalkaline pollution, as well as the detection of microbial life in serpentinization-like conditions on Earth and other planets.

Supplementary Materials: The following are available online at http://www.mdpi.com/1424-2818/11/7/103/s1, Figure S1: Phylum- and Proteobacterial class-level 16S rRNA gene relative abundances from water samples at sites 4, 5 and 7; Figure S2: Rarefaction curves for all datasets. Rarefaction for samples using RDP OTUs at the genus level using 1000 replicates; Figure S3: Analysis of similarities (ANOSIM) plot of Calumet sites, grouped by physical condition of samples. Non-overlapping notches suggest medians are distinct. Dissimilarity between groups is relatively high, and Oxic Alkaline (Serpentinomonas-rich) samples have low internal dissimilarity; Table S1: Field Sample Information, Table S2: Class-level 16S rRNA gene relative abundances from water samples.

Author Contributions: Conceptualization, W.D.S.; methodology, J.I.O., J.T.O., E.D.B., and W.D.S.; software, J.I.O., J.T.O., E.D.B., and W.D.S.; formal analysis, J.I.O.; writing-original draft preparation, J.I.O. and W.D.S.; writing-review and editing, J.I.O. and W.D.S.; visualization, J.I.O. and W.D.S.; project administration, W.D.S.

Funding: This research received no external funding

Acknowledgments: We wish to thank Karel Waska and Melissa Lenczewski for preceding geochemical work; Stefan Green for assistance with sequencing; Sarah Barmann, Karley Davidson, Amy Daly, Katie Didier, Marie Kroeger, Lori Lovell, and Kathryn Olson for their help with sampling, culturing and analysis.

Conflicts of Interest: The authors declare no conflict of interest.

\section{References}

1. Rothschild, L.J.; Mancinelli, R.L. Life in extreme environments. Nature 2001, 409, 1092. [CrossRef] [PubMed]

2. Pikuta, E.V.; Hoover, R.B.; Tang, J. Microbial Extremophiles at the Limits of Life. Crit. Rev. Microbiol. 2007, 33, 183-209. [CrossRef] [PubMed]

3. Harrison, J.P.; Gheeraert, N.; Tsigelnitskiy, D.; Cockell, C.S. The limits for life under multiple extremes. Trends Microbiol. 2013, 21, 204-212. [CrossRef] [PubMed]

4. Bonilla, J.O.; Kurth, D.G.; Cid, F.D.; Ulacco, J.H.; Gil, R.A.; Villegas, L.B. Prokaryotic and eukaryotic community structure affected by the presence of an acid mine drainage from an abandoned gold mine. Extremophiles 2018, 22, 699-711. [CrossRef] [PubMed]

5. Kalwasińska, A.; Felföldi, T.; Szabó, A.; Deja-Sikora, E.; Kosobucki, P.; Walczak, M. Microbial communities associated with the anthropogenic, highly alkaline environment of a saline soda lime, Poland. Antonie Van Leeuwenhoek 2017, 110, 945-962. [CrossRef] [PubMed]

6. Freitas, D.B.; Lima-Bittencourt, C.I.; Reis, M.P.; Costa, P.S.; Assis, P.S.; Chartone-Souza, E.; Nascimento, A.M.A. Molecular characterization of early colonizer bacteria from wastes in a steel plant. Lett. Appl. Microbiol. 2008, 47, 241-249. [CrossRef] [PubMed]

7. Kay, R.T.; Duwelius, R.F.; Brown, T.A.; Micke, F.A.; Witt-Smith, C.A. Geohydrology, Water Levels and Directions of Flow, and Occurrence of Light-Nonaqueous-Phase Liquids on Ground Water in Northwestern Indiana and the Lake Calumet Area of Northeastern Illinois; Water-Resources Investigations Report; U.S. Geological Survey: Indianapolis, IN, USA, 1996; pp. 1-26/88.

8. Colten, C.E. Industrial Wastes in the Calumet Area, 1869-1970 A Historical Geography; State Water Survey Division Report; Hazardous Waste Research and Information Center: Champaign, IL, USA; Available online: https://www.ideals.illinois.edu/handle/2142/1903 (accessed on 18 May 2019). 
9. Westphal, L.M.; Longoni, M.; LeBlanc, C.L.; Wali, A. Anglers' Appraisals of the Risks of Eating Sport-Caught Fish from Industrial Areas: Lessons from Chicago's Calumet Region. Hum. Ecol. Rev. 2008, 15, 46-62.

10. Dourson, M.L.; Chinkin, L.R.; MacIntosh, D.L.; Finn, J.A.; Brown, K.W.; Reid, S.B.; Martinez, J.M. A case study of potential human health impacts from petroleum coke transfer facilities. J. Air Waste Manag. Assoc. 2016, 66, 1061-1076. [CrossRef] [PubMed]

11. Bayless, E.R.; Greeman, T.K.; Harvey, C.C. Hydrology and Geochemistry of a Slag-Affected Aquifer and Chemical Characteristics of Slag-Affected Ground Water, Northwestern Indiana and Northeastern Illinois; Water-Resources Investigations Report; U.S. Geological Survey; Branch of Information Services [distributor]: Denver, CO, USA, 1998; pp. 1-4/67.

12. Roadcap, G.S.; Kelly, W.R.; Bethke, C.M. Geochemistry of extremely alkaline ( $\mathrm{pH}>12)$ ground water in slag-fill aquifers. Ground Water 2005, 43, 806-816. [CrossRef] [PubMed]

13. Roadcap, G.S.; Sanford, R.A.; Jin, Q.; Pardinas, J.R.; Bethke, C.M. Extremely alkaline (pH > 12) ground water hosts diverse microbial community. Ground Water 2006, 44, 511-517. [CrossRef]

14. Suzuki, S.; Kuenen, J.G.; Schipper, K.; van der Velde, S.; Ishii, S.; Wu, A.; Sorokin, D.Y.; Tenney, A.; Meng, X.; Morrill, P.L.; et al. Physiological and genomic features of highly alkaliphilic hydrogen-utilizing Betaproteobacteria from a continental serpentinizing site. Nat. Commun. 2014, 5, 3900. [CrossRef] [PubMed]

15. Woycheese, K.M.; Meyer-Dombard, D.R.; Cardace, D.; Argayosa, A.M.; Arcilla, C.A. Out of the dark: Transitional subsurface-to-surface microbial diversity in a terrestrial serpentinizing seep (Manleluag, Pangasinan, the Philippines). Front. Microbiol. 2015, 6, 44. [CrossRef] [PubMed]

16. Meyer-Dombard, D.R.; Woycheese, K.M.; Yargıçoğlu, E.N.; Cardace, D.; Shock, E.L.; Güleçal-Pektas, Y.; Temel, M. High pH microbial ecosystems in a newly discovered, ephemeral, serpentinizing fluid seep at Yanartaş (Chimera), Turkey. Front. Microbiol. 2015, 5, 723. [CrossRef] [PubMed]

17. Fones, E.M.; Colman, D.R.; Kraus, E.A.; Nothaft, D.B.; Poudel, S.; Rempfert, K.R.; Spear, J.R.; Templeton, A.S.; Boyd, E.S. Physiological adaptations to serpentinization in the Samail Ophiolite, Oman. ISME J. 2019, 1, 1750-1762. [CrossRef] [PubMed]

18. Willems, A.; Busse, J.; Goor, M.; Pot, B.; Falsen, E.; Jantzen, E.; Hoste, B.; Gillis, M.; Kersters, K.; Auling, G.; et al. Hydrogenophaga, a New Genus of Hydrogen-Oxidizing Bacteria That Includes Hydrogenophaga flava comb. nov. (Formerly Pseudomonas flava), Hydrogenophaga palleronii (Formerly Pseudomonas palleronii), Hydrogenophaga pseudoflava (Formerly Pseudomonas pseudoflava and "Pseudomonas carboxydoflava"), and Hydrogenophaga taeniospiralis (Formerly Pseudomonas taeniospiralis). Int. J. Syst. Evol. Microbiol. 1989, 39, 319-333.

19. Waska, K. Hyperalkaline Aquifers of Calumet Wetlands: Environmental Interactions between Geochemistry and Microbiology. Ph.D. Thesis, Northern Illinois University, DeKalb, IL, USA, 2014.

20. Caporaso, J.G.; Lauber, C.L.; Walters, W.A.; Berg-Lyons, D.; Lozupone, C.A.; Turnbaugh, P.J.; Fierer, N.; Knight, R. Global patterns of $16 \mathrm{~S}$ rRNA diversity at a depth of millions of sequences per sample. Proc. Natl. Acad. Sci. USA 2011, 108, 4516-4522. [CrossRef] [PubMed]

21. Wang, Q.; Garrity, G.M.; Tiedje, J.M.; Cole, J.R. Naive Bayesian Classifier for Rapid Assignment of rRNA Sequences into the New Bacterial Taxonomy. Appl. Environ. Microbiol. 2007, 73, 5261-5267. [CrossRef] [PubMed]

22. R Core Team. R: A Language and Environment for Statistical Computing; R Foundation for Statistical Computing: Vienna, Austria, 2019.

23. Lahti, L.; Shetty, S. Microbiome R Package. Available online: http://microbiome.github.com/microbiome (accessed on 16 June 2019).

24. Vu, V.Q. Ggbiplot: A Ggplot2 Based Biplot. Available online: http://github.com/vqv/ggbiplot (accessed on 16 June 2019).

25. Oksanen, J.; Blanchet, F.G.; Friendly, M.; Kindt, R.; Legendre, P.; McGlinn, D.; Minchin, P.R.; O’Hara, R.B.; Simpson, G.L.; Solymos, P.; et al. Vegan: Community Ecology Package. Available online: https:/CRAN.Rproject.org/package=vegan (accessed on 15 June 2019).

26. Bankevich, A.; Nurk, S.; Antipov, D.; Gurevich, A.A.; Dvorkin, M.; Kulikov, A.S.; Lesin, V.M.; Nikolenko, S.I.; Pham, S.; Prjibelski, A.D.; et al. SPAdes: A new genome assembly algorithm and its applications to single-cell sequencing. J. Comput. Biol. J. Comput. Mol. Cell Biol. 2012, 19, 455-477. [CrossRef] [PubMed]

27. Wu, Y.-W.; Simmons, B.A.; Singer, S.W. MaxBin 2.0: An automated binning algorithm to recover genomes from multiple metagenomic datasets. Bioinformatics 2016, 32, 605-607. [CrossRef] [PubMed] 
28. Seemann, T. Barrnap v0. Available online: https://github.com/tseemann/barrnap (accessed on 22 January 2019).

29. Camacho, C.; Coulouris, G.; Avagyan, V.; Ma, N.; Papadopoulos, J.; Bealer, K.; Madden, T.L. BLAST+: Architecture and applications. BMC Bioinform. 2009, 10, 421. [CrossRef]

30. Frank, E.; Hall, M.; Holmes, G.; Kirkby, R.; Pfahringer, B.; Witten, I.H.; Trigg, L. Weka-A Machine Learning Workbench for Data Mining. Data Min. Knowl. Discov. Handb. 2009, 1269-1277.

31. Becraft, E.D.; Dodsworth, J.A.; Murugapiran, S.K.; Ohlsson, J.I.; Briggs, B.R.; Kanbar, J.; De Vlaminck, I.; Quake, S.R.; Dong, H.; Hedlund, B.P.; et al. Single-Cell-Genomics-Facilitated Read Binning of Candidate Phylum EM19 Genomes from Geothermal Spring Metagenomes. Appl. Environ. Microbiol. 2016, 82, 992-1003. [CrossRef] [PubMed]

32. Tamura, K.; Stecher, G.; Peterson, D.; Filipski, A.; Kumar, S. MEGA6: Molecular Evolutionary Genetics Analysis Version 6.0. Mol. Biol. Evol. 2013, 30, 2725-2729. [CrossRef] [PubMed]

33. Hierarchy Browser. Available online: http://rdp.cme.msu.edu/hierarchy/hb_intro.jsp (accessed on 27 June 2019).

34. Home-Gene-NCBI. Available online: https://www.ncbi.nlm.nih.gov/gene/ (accessed on 27 June 2019).

35. Aziz, R.K.; Bartels, D.; Best, A.A.; DeJongh, M.; Disz, T.; Edwards, R.A.; Formsma, K.; Gerdes, S.; Glass, E.M.; Kubal, M.; et al. The RAST Server: Rapid annotations using subsystems technology. BMC Genomics 2008, 9, 75. [CrossRef] [PubMed]

36. Parks, D.H.; Imelfort, M.; Skennerton, C.T.; Hugenholtz, P.; Tyson, G.W. CheckM: Assessing the quality of microbial genomes recovered from isolates, single cells, and metagenomes. Genome Res. 2015, 25, 1043-1055. [CrossRef] [PubMed]

37. Baas-Becking, L.G.M. Geobiologie; of Inleiding tot de Milieukunde; WP Van Stockum \& Zoon NV: Den Haag, The Netherlands, 1934.

38. Schrenk, M.O.; Brazelton, W.J.; Lang, S.Q. Serpentinization, Carbon, and Deep Life. Rev. Mineral. Geochem. 2013, 75, 575-606. [CrossRef]

39. Crespo-Medina, M.; Twing, K.I.; Sánchez-Murillo, R.; Brazelton, W.J.; McCollom, T.M.; Schrenk, M.O. Methane Dynamics in a Tropical Serpentinizing Environment: The Santa Elena Ophiolite, Costa Rica. Front. Microbiol. 2017, 8, 916. [CrossRef]

40. Horikoshi, K. Alkaliphiles: Some Applications of Their Products for Biotechnology. Microbiol. Mol. Biol. Rev. 1999, 63, 735-750.

41. Banciu, H.L.; Muntyan, M.S. Adaptive strategies in the double-extremophilic prokaryotes inhabiting soda lakes. Curr. Opin. Microbiol. 2015, 25, 73-79. [CrossRef]

42. Detkova, E.N.; Boltyanskaya, Y.V. Osmoadaptation of haloalkaliphilic bacteria: Role of osmoregulators and their possible practical application. Microbiology 2007, 76, 511-522. [CrossRef]

43. Brazelton, W.J.; Morrill, P.L.; Szponar, N.; Schrenk, M.O. Bacterial Communities Associated with Subsurface Geochemical Processes in Continental Serpentinite Springs. Appl. Environ. Microbiol. 2013, 79, 3906-3916. [CrossRef] [PubMed]

(C) 2019 by the authors. Licensee MDPI, Basel, Switzerland. This article is an open access article distributed under the terms and conditions of the Creative Commons Attribution (CC BY) license (http://creativecommons.org/licenses/by/4.0/). 